\title{
Florida Sleeve for type A dissection
}

\author{
Kirsten A. Freeman, Thomas M. Beaver, Eric I. Jeng, Tomas D. Martin, George J. Arnaoutakis \\ Division of Cardiovascular Surgery, Department of Surgery, University of Florida, Gainesville, FL, USA \\ Contributions: (I) Conception and design: All authors; (II) Administrative support: All authors; (III) Provision of study materials or patients: All \\ authors; (IV) Collection and assembly of data: All authors; (V) Data analysis and interpretation: All authors; (VI) Manuscript writing: All authors; (VII) \\ Final approval of manuscript: All authors. \\ Correspondence to: Kirsten A. Freeman, MD. Division of Cardiovascular Surgery, University of Florida, Gainesville, FL 32610-0129, USA. \\ Email: Kirsten.Freeman@surgery.ufl.edu.
}

\begin{abstract}
In properly selected patients, an aortic root repair with valve salvage is a viable alternative to root replacement. Acute type A aortic dissections are often emergency operations with a high complexity. These cases are particularly difficult when the aortic root is enlarged, but the aortic valve leaflets and morphology are normal. In the setting of an acute ascending aortic dissection and enlarged aortic root, preservation of the valve via the use of the Florida Sleeve root repair technique is an alternative to root replacement. We present a case of our standard Florida Sleeve root repair in a patient with an ascending aortic aneurysm of $6.0 \mathrm{~cm}$ and an aortic root of $5.3 \mathrm{~cm}$ with moderate aortic insufficiency. The patient is a healthy 57 -year-old male that had normal trileaflet anatomy but central aortic insufficiency appearing to be related to his root dilation on pre-operative echocardiogram. The Florida Sleeve technique for root remodeling with preservation of the aortic valve and sinuses is a technique for saving the aortic valve while narrowing the annulus and sinotubular junction. Familiarity with root replacement and valve preserving techniques during non-emergency setting is crucial in order to complete the procedure in an efficient manor during an aortic dissection operation.
\end{abstract}

Keywords: Florida Sleeve; aortic root; type A dissection

Received: 02 March 2020; Accepted: 22 May 2020; Published: 20 October 2021.

doi: 10.21037/jovs-20-75

View this article at: http://dx.doi.org/10.21037/jovs-20-75

\section{Introduction}

Techniques for aortic root replacement with valve salvage are complex surgical procedures (1). When facing a patient with a dilated aortic root with or without aortic insufficiency but normal valve leaflet morphology, valve sparing techniques are feasible options (2-4). Management of the enlarged aortic root becomes even more complex in the setting of an acute ascending aortic dissection (5-7). Acute type A aortic dissections are often emergency operations with a high complexity $(8,9)$. In properly selected patients with an aortic dissection, an aortic root repair with valve salvage is a viable alternative to root replacement $(10,11)$. Valve-sparing root replacement utilizing reimplantation technique has the added benefit of stabilizing the annulus (4).

The Florida Sleeve technique for root remodeling with preservation of the aortic valve and sinuses is a well- established technique for saving the aortic valve while narrowing the annulus and sinotubular junction (12-15). Allowing the patient to keep their native aortic valve decreases the risk of bleeding issues related to mechanical valves as well as circumvents the potential need for the future re-intervention with a bioprosthetic valve (16). Additionally, the Florida Sleeve root repair technique is a particularly good option in patients who have enlarged aortic root and aberrant coronary anatomy. The ability to salvage the valve but not needing to re-implant the coronary buttons decreases the clamp time, which the importance of operative time cannot be understated in the setting of an emergency surgery.

\section{Patient selection}

The Florida Sleeve technique has been employed at our 


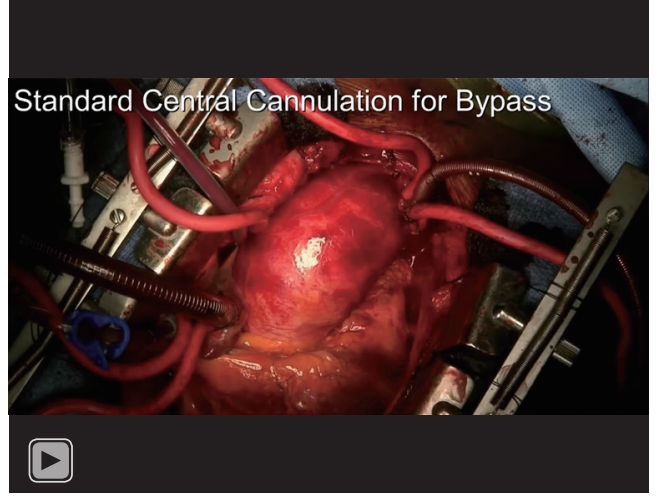

Video 1 Florida Sleeve root repair technique in a 57-year-old male with $5.3 \mathrm{~cm}$ aortic root and moderate aortic insufficiency.

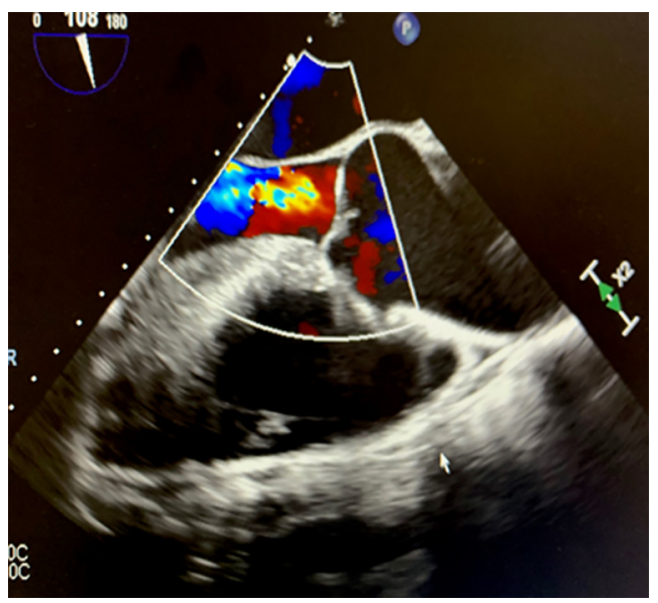

Figure 1 Aortic root enlargement and central aortic insufficiency seen on pre-operative echocardiogram.

institution in the setting of acute type A aortic dissections with good technical success. We present a video (Video 1) of our standard Florida Sleeve root repair in a patient with slightly offset coronary arteries with an ascending aortic aneurysm of $6.0 \mathrm{~cm}$ and an aortic root of $5.3 \mathrm{~cm}$ with moderate aortic insufficiency pre-operatively. The patient is a healthy 57 -year-old male that had normal trileaflet anatomy but central aortic insufficiency appearing to be related to his root dilation on pre-operative echocardiogram (Figure 1). For preserving the aortic valve in the setting of an acute aortic dissection, it is imperative that the valve leaflets be of normal morphology and the aortic insufficiency be related to the enlargement of the aortic root. If the insufficiency is related to a valve leaflet abnormality, the patient is best served with a root

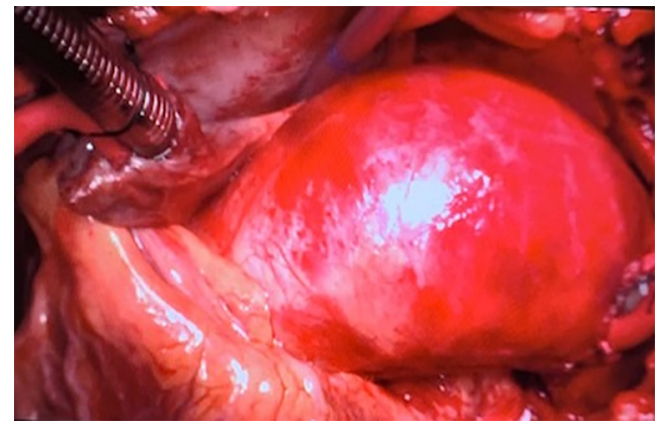

Figure 2 Intraoperative image of ascending aortic and root aneurysm.

replacement. Familiarity with root replacement and valve preserving techniques during non-emergency setting is crucial in order to complete the procedure in an efficient manor during an aortic dissection operation.

\section{Pre-operation preparation/equipment}

Standard open-heart equipment should be available. Transesophageal echocardiography, central line, swanganz catheter, arterial line, foley catheter should be utilized. Graft conduits should be available. We typically use a $32 \mathrm{~mm}$ or $34 \mathrm{~mm}$ Dacron Gelweave ${ }^{\mathrm{TM}}$ Valsalva graft (Terumo Aortic Vascutek Ltd., Scotland, UK) for creation of the sleeve root repair in large aortic roots.

\section{Procedure}

\section{Standard central cannulation}

Patient is cannulated for cardiopulmonary bypass centrally with an aortic cannula placed in the distal ascending aorta/ proximal arch and a dual stage venous cannula placed into the inferior vena cava via the right atrium. Additionally, a retrograde coronary sinus catheter via the right atrium and a left ventricular vent via the right superior pulmonary vein is placed (Figure 2). If the operation is proceeding in the setting of a dissection, confirmation of placement of the aortic cannula into the true lumen is imperative. The aorta is cross-clamped proximal to the aortic cannula. In an elective operation without an aortic dissection, antegrade cardioplegia is attempted in the setting of up to moderate aortic regurgitation, and then switched to retrograde cardioplegia after one liter of antegrade. In the setting of a dissection, typically retrograde cardioplegia is utilized to arrest the heart, followed by coronary ostial antegrade 
cardioplegia. Retrograde cardioplegia is given every 15-20 minutes. The patient is cooled to the desired temperature, in this case the patient was cooled to 18 degrees Celsius for deep hypothermic circulatory arrest for a hemiarch replacement.

\section{Inspecting the valve}

After the heart arrested the aorta is opened and the valve is visualized. Confirmation of normal valvular morphology must be made. After the leaflets are confirmed normal, the valve is inspected for coaptation to determine if root remodeling would improve the aortic insufficiency. Attention is then turned to the location of the coronary ostia. If the coronary ostia are dissected then consideration for full root replacement will need to be made. The size of the annulus is determined by sizing with Hegar dilators or valve sizers and a graft is selected. For a large aortic root, a $32-34 \mathrm{~mm}$ Valsalva graft is used. Smaller grafts may be needed for smaller roots.

\section{Mobilization of the proximal coronary arteries}

Circumferentially the root is mobilized down to the aortic annular level. This mobilization includes the proximal coronary arteries. The coronary arteries are circumferentially dissected at their insertion into the aorta. This will allow the Dacron graft to be secured underneath the coronary arteries later.

\section{Creating coronary "keyboles" in the graft}

After the proximal coronary arteries are mobilized, the coronary ostia are identified and determination is made as to their location in relation to the commissures. Once a determination is made on their relation then a "keyhole" cut it made into the Dacron Valsalva graft in a likewise position. If the coronary ostia are closer to one of the commissures then the "keyhole" is offset to ensure proper placement around the proximal coronary artery.

\section{Securing the graft}

Three to four subannular horizontal mattress pledgeted sutures are placed that will secure the position of the graft. These sutures are placed below the aortic annulus and then directed outside the aorta. These subannular sutures are the passed through the base of the Valsalva graft. Attention is then turned to securing the graft below the proximal coronary arteries. Horizontal mattress sutures are placed on one side of the base of the "keyhole", both free sutures passed below the coronary artery, and then driven out the other side of the graft at the base of the "keyhole". The distal end of the graft is then cut down by a few centimeters to aide in positioning.

\section{Positioning the graft}

The graft is then placed over the root as a sleeve. The graft must be adequately positioned with the graft down to the annulus and below each coronary artery. A 26-mm Hegar dilator is placed, taking care not to injure the aortic valve, through the annulus to prevent narrowing while tying the sutures. The subannular sutures and coronary keyhole sutures are tied down. The coronary arteries are assessed for patency and potential need for lengthening the coronary keyhole incision.

\section{Completing the root repair}

Commissural resuspension horizontal pledgeted sutures are placed through the aorta a few millimeters above the commissures and out of the graft. A felt strip is then sutured in place by use of a running horizontal mattress at the sinotubular junction securing the aorta to the graft circumferentially. The commissural resuspension sutures are tied.

\section{Assessing the sleeve}

The valve is the inspected for coaptation (Figure 3). The aorta is cut to the level of the sinotubular junction, and likewise the graft is cut to the level of the sinotubular junction. The repair is completed. The graft from the ascending aortic replacement is then sutured to the sleeve repair with a running polypropylene suture.

\section{Final evaluation of root repair}

After de-airing and removal of the cross clamp, the repair is accessed with the heart beating. Location of the proximal coronary arteries are again inspected and confirmation is made that there is no impingement of outflow. The valve is assessed by transesophageal echocardiogram to determine the new level, if any, of aortic insufficiency (Figure 4). The patient is separated from cardiopulmonary bypass, 


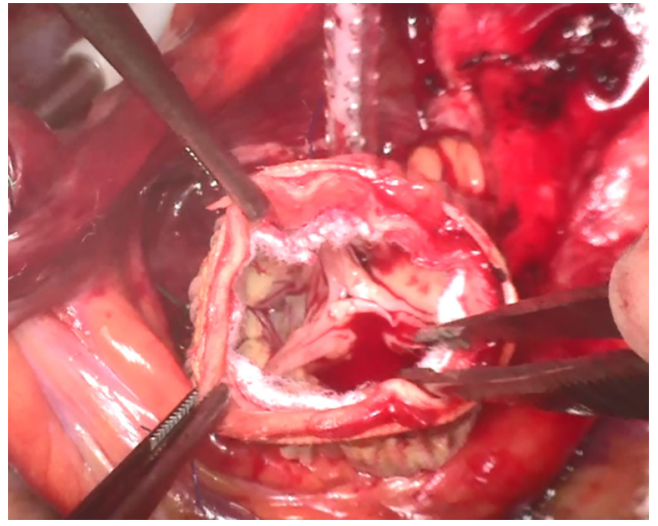

Figure 3 Valvular coaptation assessed after completed Florida Sleeve root repair.

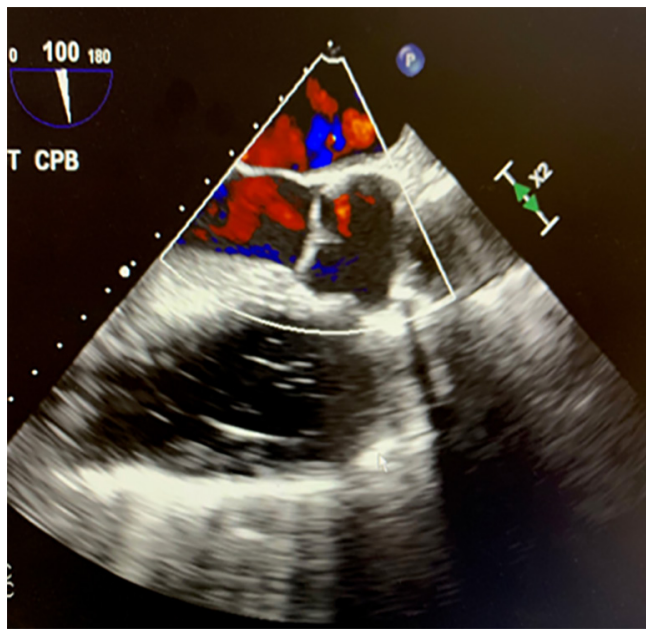

Figure 4 Transesophageal echocardiogram image showing no aortic insufficiency after complete of Florida Sleeve root repair.

decannulated, and closed per standard protocols (Figure 5).

\section{Conclusions}

When facing a patient with a dilated aortic root with aortic insufficiency, but normal valve leaflet morphology, valvesparing root replacements can be a suitable option. With proper patient selection, an aortic root repair with valve salvage can be accomplished in the setting of an acute aortic dissection. Knowledge of and experience with the Florida Sleeve technique for valve-preservation in the setting of enlarged aortic root is important, and particularly in the application of root repair strategies during surgery for acute ascending aortic dissection.

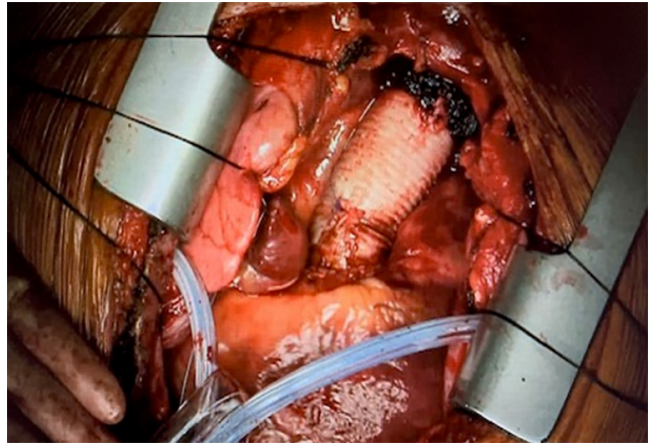

Figure 5 Intraoperative image of completed Florida Sleeve root repair.

\section{Acknowledgments}

We would like to acknowledge Division of Cardiovascular Surgery, Department of Surgery, University of Florida for their ongoing support.

Funding: None.

\section{Footnote}

Provenance and Peer Review: This article was commissioned by the editorial office, Fournal of Visualized Surgery for the series "Advancement in the Surgical Treatment of Aortic Dissection". The article has undergone external peer review.

Conflicts of Interest: All authors have completed the ICMJE uniform disclosure form (available at https://jovs. amegroups.com/article/view/10.21037/jovs-20-75/coif). The series "Advancement in the Surgical Treatment of Aortic Dissection" was commissioned by the editorial office without any funding or sponsorship. GJA served as the unpaid Guest Editor of the series. The authors have no other conflicts of interest to declare.

Ethical Statement: The authors are accountable for all aspects of the work in ensuring that questions related to the accuracy or integrity of any part of the work are appropriately investigated and resolved. Written informed consent was obtained from all patients for publication of this article and any accompanying images/videos.

Open Access Statement: This is an Open Access article distributed in accordance with the Creative Commons Attribution-NonCommercial-NoDerivs 4.0 International License (CC BY-NC-ND 4.0), which permits the non- 
commercial replication and distribution of the article with the strict proviso that no changes or edits are made and the original work is properly cited (including links to both the formal publication through the relevant DOI and the license). See: https://creativecommons.org/licenses/by-nc-nd/4.0/.

\section{References}

1. David TE, Armstrong S, Ivanov J, et al. Results of aortic valve-sparing operations. J Thorac Cardiovasc Surg 2001;122:39-46.

2. Casselman FP, Tan ES, Vermeulen FE, et al. Durability of aortic valve preservation and root reconstruction in acute type A dissection. Ann Thorac Surg 2000;70:1227-33.

3. David TE. Aortic valve sparing operations. Ann Thorac Surg 2002;73:1029-30.

4. Sultan I, Komlo CM, Bavaria JE. How I Teach a Valve-Sparing Root Replacement. Ann Thorac Surg 2016;101:422-5.

5. Leshnower BG, Chen EP. When and how to replace the aortic root in type A aortic dissection. Ann Cardiothorac Surg 2016;5:377-82.

6. Beckmann E, Martens A, Pertz J, et al. Valve-sparing David I procedure in acute aortic type A dissection: a 20-year experience with more than 100 patients. Eur J Cardiothorac Surg 2017;52:319-24.

7. Yang B, Norton EL, Hobbs R, et al. Short- and long-term outcomes of aortic root repair and replacement in patient undergoing acute type A dissection repair: Twenty year

doi: $10.21037 /$ jovs-20-75

Cite this article as: Freeman KA, Beaver TM, Jeng EI, Martin TD, Arnaoutakis GJ. Florida Sleeve for type A dissection. J Vis Surg 2021;7:38. experience. J Thorac Cardiovasc Surg 2019;157:2125-36.

8. Di Marco L, Leone A, Murana G, et al. The application of the "KISS principle" for the treatment of type A acute aortic dissection: is this always right? J Thorac Dis 2018;10:S3884-6.

9. Auer J, Berent R, Eber B. Aortic dissection: incidence, natural history and impact of surgery. J Clin Basic Cardiol 2000;3:151-4.

10. Tanaka H, Ikeno $\mathrm{Y}$, Abe $\mathrm{N}$ et al. Outcomes of valvesparing root replacement in acute type A aortic dissection. Eur J Cardiothorac Surg 2018;53:1021-6.

11. Leontyev S, Borger MA. David operation for type A aortic dissection: risk and rewards. Eur J Cardiothorac Surg 2017;52:325-6.

12. Hess PJ Jr, Klodell CT, Beaver TM, et al. The Florida Sleeve: a new technique for aortic root remodeling with preservation of the aortic valve and sinuses. Ann Thorac Surg 2005;80:748-50.

13. Hess P, Caranasos T, Siegal S, et al. Valve-sparing repair of aortic root aneurysms: an update of the Florida Sleeve. Heart Surg Forum 2014;17:E10-2.

14. Aalaei-Andabili SH, Martin T, Hess P, et al. Florida Sleeve is durable and improves aortic valve function in Marfan syndrome patients. Ann Thorac Surg 2017;104:834-9.

15. Aalaei-Andabili SH, Martin TD, Hess PJ, et al. The Florida Sleeve procedure is durable and improves aortic valve function. Aorta 2019;7:49-55.

16. Leone A, Murana G, Di Marco L, et al. Aortic valve repair in type A dissection. J Vis Surg 2019;5:79. 